\title{
Knowledge, Attitudes and Practices of Nurses Regarding Client Safety at Maternal and Child Health Care Centers
}

\author{
Sherehan EL Sayid Abo khaph ${ }^{1}$, Nahla Said Mahmoud ${ }^{2}$, Samia .E.Khaton ${ }^{3}$. \\ 1Baccalaureate of nursing, Faculty of Nursing, Tanta University, Egypt \\ ${ }^{2}$ Lecturer of Community Health Nursing, Faculty of Nursing, Tanta University, Egypt \\ ${ }^{3}$ Assistant Professor of Community Health Nursing, Faculty of Nursing, Tanta University Egypt
}

\begin{abstract}
Background: Patient safety is the cornerstone of high-quality health care. Nurses play a critical role in ensuring patient safety by monitoring patients, detecting errors, understanding care processes, and performing countless other tasks to ensure patients receive high-quality care. Aim of this study: Assess knowledge, attitudes and practices of nurses toward client safety at maternal and child health care centers $(\mathrm{MCH})$. Subjects and methods: A Convenience sample of 120 nurses included in the study. Design: Descriptive study design.
\end{abstract} Setting: All seven MCH centers at Tanta city. Tools: Two tools were used, Tool (I) Structured interview schedule: which developed by the researcher and is consisted of three parts as follows, nurses socio demographic data, their knowledge toward patient safety and nurses attitudes by using Safety Attitude Questionnaire ambulatory version (SAQ- AV) toward patient safety Tool (II) An observational checklist regarding Nurses' practices: This tool was done by using checklist that was developed and constructed by researcher based on related literature review and the nature of each clinic. Results: more than one third (40.8\%) of studied nurses had good total knowledge score and the majority (89.2\%) of them had a positive attitude. The majority $(95.8 \%, 90.9 \%)$ of studied nurses' total practice levels were satisfactory in vaccination clinic and family planning clinic. There was a significant relation was found between socio demographic data and total knowledge and attitude scores of the studied nurses. Conclusion: the more knowledge health care professionals have about patient safety, the more positive their attitudes and the better their skills regarding patient safety Recommendations: It was recommended that all nurses working in primary health care settings should complete regular periodic in-services training programs to keep them up to date regarding patients' safety culture and safety practices.

Keywords: patient safety, knowledge, attitude, practices, Maternal and Child health care. 


\section{Introduction}

Patient safety has been marked as a key priority of healthcare in recent decades not only because of the recognition of the extent and severity of the problem but equally because of successful interventions can reduce, mitigate or prevent known harm. The challenge for healthcare match, prioritize and implement safety interventions that provide effective, evidence-based, relevant, achievable, measurable and best value protection from harm across the care spectrum. Safety is a fundamental principle of patient care and a critical component of quality management ${ }^{(1-2)}$.

According to (WHO) patient safety is defined as "the absence of preventable harm to a patient during the process of health care". Patient safety is the reduction in the risk of unnecessary harm associated with health care, to an acceptable minimum ${ }^{(3)}$. Health care associated harm is a harm that arising from or associated with plans or actions taken during the provision of health care, rather than that associated with an underlying disease or injury. Patient safety often referred to as a safety climate or safety culture. (4)

Patient safety culture "the product of individual and group values, attitudes, perceptions, competencies and patterns of behavior that determine the compliance to, the style and efficiency of, an organization's health and safety management. However, this needs to be balanced with accountability in recognition that not all mistakes should go unpunished. The culture allows healthcare organizations to determine how they might deal with clinical errors, thus striking a balance between mistakes and accountability ${ }^{(5)}$.

The concept of patient safety in primary care, not only focused on the primary care practice as the environment or setting for patient safety to be empowered, but also the health care system (e.g., issues associated with fragmentation of care or continuity of care between acute and primary care settings) and community (e.g., issues associated with community pharmacy or other community-level health care professionals) as determinants of safety ${ }^{(6)}$.

According to (WHO) (2018) globally health safety failures in primary and ambulatory care are common; many of them can be avoided. Estimates show that as many as 20\%:25\% of the general population harmed in developed and developing countries respectively. Some estimates say that as many as 4 out of 10 patients are harmed in the primary/ambulatory setting. Most harmful are errors related to diagnosis and prescription and the use of medicines. Up 
to $80 \%$ of harm in primary and ambulatory settings can be prevented ${ }^{(7)}$.

Agreeing to The World Health Organization (WHO), patient safety program has launched the "Safer Primary Care" project, which focuses on risk exposures, harms that are preventable, and how to maintain patients at essential care level as infection control program, communication skills that maintain accuracy of data, identification system in all parts of $\mathrm{MCH}$ center as prenatal, postnatal, dental clinic, immunization clinic and family planning ${ }^{(8)}$.

In Egypt, patient safety culture still has numerous areas for enhancement that require continuous evaluation and monitoring to attain a safe environment both for patients and health-care providers. Patient safety culture is an organizational culture that develops a positive environment in which patient safety is likely to happen. In Egypt, there is increasing interest in patient safety in the presence of a general lack of perception of the problem. ${ }^{(9-10)}$.

Maternal and child healthcare $(\mathrm{MCH})$ is one of the most viable area in the sustainable development goals. Maternal and Child health care Centers $(\mathrm{MCH})$ services refer to the care provided for children during growth and development period and care for women during pregnancy, childbirth and postpartum period. Such services involve not only medical interventions on illness conditions, but also health promotion activities and preventive care. Integration of these services is essential to ensure high standard of care, which often includes many providers and cross-organizational collaborations. Unfortunately, MCH clients (women and children) are usually disadvantaged in access to healthcare due to their relatively low socioeconomic status (11)

The aim of the patient safety is to decreases the chance of injury or harm to patient from the structure and process of care by detection of safety problems, preventive and corrective action, processes to diminish action, setting up of corrective action plan and ongoing action measurement to ensure effective action. Safer PHC services throughout the world strive to provide care to people when they are unwell and assist them to stay well. Primary care services are increasingly at the heart of integrated people-centered health care in many countries. They provide an entry point into the health system, ongoing care coordination and a person focused approach for people and their families. Accessible and safe primary care is essential to achieving universal health coverage. Health services 
work hard to provide safe and high quality care, but sometimes people are inadvertently harmed. Unsafe health care has been recognized as a global challenge and much has been done to understand the causes, consequences and potential solutions to this problem ${ }^{(12)}$.

However, the majority of this work up to now has focused on hospital care and there is, as a result, far less understanding about what can be done to improve safety in primary care. Assessment of current safety culture in a primary healthcare organizations especially $\mathrm{MCH}$ centers is the first step to identify the most problematic areas for improvement.

(10) Since healthcare staff knowledge, attitudes and pattern of behaviors are critical in the promotion of the workplace climate needed to secure an organizational culture of safety.

Three characteristics of the concept patient safety in primary care they are including Knowledge about safe practices among healthcare providers; deliver safe patient care in primary care that is free from harm with using of technology and compliance to origination policies of care: primary health care provider commitment to patient safety demonstration such as incident reporting and provide safe patient environment $^{(13)}$.
Community health nurse play a critical role in preserving and ensuring patient safety due to the nature of their work. Nurses play a critical role in ensuring patient safety by monitoring patients, detecting errors, understanding care processes, and performing countless other works to ensure patients receive highquality care. Moreover, community health nurses should be assessed regularly for providing safety measures and detailed for nursing mistakes for avoiding risk factors which are threaten the patient safety. ${ }^{(14)}$

Nurses associate with team members to discuss the best safe treatment plan for the patients. Thus, nurses review the patients' plan of care and identify safety issues to discuss with team members. For example, nurses maintain effective communication with team members and patients to facilitate positive results ${ }^{(5)}$. The involvement of nurses in patient care rounds will promote safer outcomes.

Nurses also have a role in maintaining National Patient Safety Goals, through preventing medication Errors and to use medicines safety. Nurses should follow their facilities' policies during medication administration to prevent medication errors. For example, nurses should identify patients correctly, follow the 10 medication Rights during medication review, and educate all patients about the 
side effects of each medication and expected outcomes . Moreover, nurses can help in preventing infection through following guidelines to protect patients from hospital-acquired infections, such as hand hygiene, needle stick or sharp injuries prevention and carefully handle sharps and clinical waste carefully at all times ${ }^{(16-}$ 17). In addition nurses identify patients at risk for falls and conduct appropriate assessment that enables applying individualized measures to avoid falls ${ }^{(18)}$

For nursing practice, it is recommended that patient safety among primary care practitioners should be evaluated from time to time to make sure that they are efficient enough in order to deliver health care. ${ }^{(1)}$.

\section{Significance of the study}

Until now, only few organizations in Egypt have assessed how much their staff culture backs up patient safety. Health care providers at primary health care (PHC) facilities should have sufficient background knowledge and deliver practices maintain patient safety in order to minimize the incidence of adverse events especially when PHCs are considered as the first line of health care provision $^{(19)}$.

\section{Aim of the study}

The aim of this study is to
Assess knowledge, attitudes and practices of nurses toward client safety at maternal and child health care centers.

\section{Research questions}

- What are the levels of nurses' knowledge, attitudes and practices regarding client safety at maternal and child health care centers?

\section{Subjects\& Methods}

Study design: Descriptive study was used in this study.

\section{Setting of the study}

This study was conducted at all the maternal and child health care centers at Tanta city. (There were $7 \mathrm{MCH}$ in Tanta city include $\mathrm{MCH}$ centers in El-Embaby, Segar, kohafa, El-Agezy, El- mantka elazharia, Tal-elhadadeen and bottros center).

\section{Subjects}

A convenience number of all 120 nurses who worked in dental, antenatal, family planning, child out patient, child follow up and immunization clinics and emergency clinic in the previous mentioned centers were included in the study as follow: -

\begin{tabular}{|l|c|}
\hline Mch centers & No of nurses \\
\hline Bottros center & 20 \\
\hline El-Embaby & 15 \\
\hline Segar & 25 \\
\hline kohafa & 15 \\
\hline El-Agezy & 15 \\
\hline
\end{tabular}




\begin{tabular}{|l|c|}
\hline El- mantka elazharia & 15 \\
\hline Tal-elhadadeen & 15 \\
\hline Total & 120 \\
\hline
\end{tabular}

Tools of the study:

Two tools were used in this study:

Tool (I) "Structured Interview Schedule

" This tool was developed by the researcher after review of the relevant literature to assess nurses socio demographic data, their knowledge toward patient safety and nurse's attitudes toward patient safety. It included three parts as follow:

\section{Part 1: Socio-demographic data of the} nurses

It includes socio demographic data that contain the following variables: age, sex, years of experience, job title, type of clinic in which the nurse worked $^{(20-21-22-23)}$.

\section{Part2: Nurses' knowledge toward} client safety such as

Meaning of patient safety, Elements or components of patient safety, Importance of patient safety, International goals of patient safety in $\mathrm{MCH}$. It was written in the form of (20) multiple choice questions

Scoring system of nurse's knowledge toward client safety was calculated as follow

-Each question of knowledge part was scored as: -
- Complete correct answer was $\operatorname{taken}(2)$

-Incomplete correct answer was taken(1)

-Don't know was taken (zero)

The Total score of knowledge was classified as

-Good $\rightarrow>70 \%$ of the total score ( $>$ 28 degree)

-Fair $\rightarrow 60-70 \%$ of the total score $(24$

- 28 degree)

-Poor $\rightarrow<60 \%$ of the total score $(<24$

degree)

Part 3: Nurses attitudes toward patient safety

-This part was done by using Safety Attitude Questionnaire ambulatory version (SAQ- AV) that was adopted by the researcher. It was developed by Modak et.al in 2007.It measured nurse's attitude toward patient safety in primary health care centers where it has shown to be a reliable tool for comparing attitudes across different professional groups of health care providers outside hospitals. ${ }^{(24)}$ -Safety Attitudes Questionnaire measure nurse's attitude toward patient safety culture and also measure safety-related attitudes concerning teamwork climate, job satisfaction, perceptions of management, safety climate, working conditions and stress recognition. This scale consisted of 30 item. 
a- Teamwork climate: the quality of the relationship and cooperation amongst staff members (items from 1-6).

b-Safety climate: the professionals' perception regarding organizational commitment to patient safety (items from 7-13)

c- Job satisfaction: positive perception of workplace (items from 14-18).

d- Stress perception: recognizing the stress factors that might influence work performance (items from 19-22).

e- Perception of primary health care setting management: approval of the hospital management or actions regarding the unit in which the professional works (items from 23-26).

f- Working conditions: (items from 2730)

\section{Scoring system of patient safety attitude} questionnaire was done as follow:

-The scale was designed in three -point Likert-type scale, ranging between "agree", "unsure", "disagree". Nurse who was responded by " Agree answer " was given a score (Two) " Unsure answer" was given a score (one) and the nurse who was responded" Disagree answer " was given a score (zero). Total score percentage of the scale ranged from (0) $0 \%$ the worst attitude to (60) $100 \%$ the best attitude.

The Total score of nurses' attitude was classified as follow
- Positive attitude was $\geq 70 \%$ of the total score. ( $\geq 42$ degree)

- Negative attitude was $<70 \%$ of total score. $(<42$ degree $)$

Tool II: An observational checklist regarding Nurses' practices

- This tool was done by using checklist that was developed and constructed by researcher based on related literature review ( 25 - 26-27) and the nature of each clinic. It was used to assess nurses' practice toward maintaining patient safety in every studied clinic - This checklist was covered practices related to the following items in each clinic.

- Patient identification- Patient communication- Safety environment Infection control precautions done for each procedure.

The Scoring of the observational checklist was done as follows

-Complete done correct practice was taken two.

-Incomplete done correct practice was taken one.

-Not done practice was taken zero.

- Total practice score was classified as follows

- Satisfactory $\geq 70 \%$ of the total practice score.

- Unsatisfactory $<70 \%$ of the total practice score. 


\section{Method}

\section{1- Administrative process}

1. An official permission to carry out the study was obtained from the Dean of the faculty of nursing Tanta university to the responsible authorities of maternal and child health centers.

\section{2- Ethical consideration}

a-The agreement of the ethical committee of the faculty of nursing was taken before conducting the study.

b- Informed consent was obtained from every nurse included in the study after explanation of the aim of the study and assuring them of confidentiality of collected data.

c- Confidentiality and anonymity was maintained by the use of code number instead of name and the right of withdrawal was reserved.

\section{3- Tools development}

Tool I (Structured Interview Schedule ) . part 1 and 2 were developed by the researcher based on relevant literature review for collection of baseline data and part 3 using Safety Attitude Questionnaire ambulatory version (SAQ- AV) by Modak et.al in 2007 that was adopted by the researcher. Arabic translation of this tool was done by the researcher.

Tool II: An observational checklist regarding Nurses' practices which was developed and constructed by researcher based on related literature review and the nature of each clinic.

\section{4- Content validity}

Tools of study was tested for their face and content validity by a jury of five professor's expertise in the field of community health nursing before conducting the study after their translation into Arabic language and content validity was ranged from $90 \%$ to $100 \%$ to the questionnaires

\section{5- A pilot study}

A pilot study was carried out on $(10 \%$ of subject) which include 12 nurse to test the tool for its clarity and understandability, feasibility and applicability of the tools.

\section{6- Reliability of the tools}

All tools of the study were tested for reliability using Cronbach alpha test and based on the results of the pilot study.

- Cronbach's Alpha for first tool is $\mathbf{0 . 9 0 2}$ for 55 items applied on 12 nurses. Cronbach's Alpha for second tool is $\mathbf{0 . 8 9 4}$ for 83 items applied on 12 nurses. Cronbach's Alpha for the tools in total is 0.871 for 138 items applied on 12 nurses.

\section{7- Data collection}

- Data was collected during the morning shift according to $\mathrm{MCH}$ rules. The studied nurses were asked to participate in the study after establishing trusting relationship and explaining the aim of the study. 
- researcher met nurses individually in selected clinics in each $\mathrm{MCH}$ centers according to schedule of each center to collect related to nurses knowledge toward patient safety and nurses attitudes toward patient safety using tool ( I) .

- The researcher observed nurses' clinical practices related to enhancing patient safety, directly in each clinic using an observational checklist (toolII).

- The researcher spends around 3 days 1 week for 2 weeks in each center.

- $\quad$ These methods carried out to all 7 $\mathrm{MCH}$ centers based on the working days of each center.

- Data collection was conducted over a period of three months and half, (started from first of September 2020 to the half of December 2020).

- Finally, after data collection, data was coded, analyzed then tabulated under the direction of a statistician to obtain results to answer the research questions.

\section{8- Statistical analysis}

The collected data were organized, tabulated and statistically analyzed using SPSS software statistical computer package version 26. For quantitative data, the range, mean and standard deviation were calculated. For qualitative data, comparison was done using Chi-square test $\left(\chi^{2}\right)$. Correlation between variables was evaluated using Pearson and Spearman's correlation coefficient r. A significance was adopted at $\mathrm{P}<0.05$ for interpretation of results of tests of significance (*). Also, a highly significance was adopted at $\mathrm{P}<0.01$ for interpretation of results of tests of significance $(* *)$.

\section{Results}

\section{Part 1: Socio - demographic}

\section{characteristics of the studied nurses}

Table 1 illustrates percentage distribution of studied nurses according to socio demographic characteristics. The table showed that, the mean age of studied nurses was (46.316.573 years). Half of the studied nurses $(50.0 \%)$ were in the age group from 40 to less 50 years old, while only $15.0 \%$ in the age group from 30 to less 40 years old. As regards to level of qualification, the majority $(87.5 \%)$ of the studied nurses were technician nursing (3 years). Nearly half (47.5\%) of them had years of experience from 20 to 30 years. While more than one third (38.3\%) of them had work years of experience ranged from 30 years to less than 40 years.

\section{Part 2: knowledge toward client safety in $\mathrm{MCH}$ center}

Table 2 reveals the distribution of the studied nurses according to their knowledge toward client safety in $\mathrm{MCH}$ 
center. The table showed that, three quarters $(75 \%)$ of the studied nurses gave a complete correct answer about the instructions that must be followed up by nursing staff to prevent the spread of infection in the clinics of the center and nearly more than two thirds $(70.0 \%$ and $68.3 \%$ respectively) of them gave a complete correct answer about safety box specifications for the disposable of pins and sharp instruments in the clinics and nursing practices to prevent recipient from falling risks in the center respectively).

More than half $(65.8 \%, 63.3 \%, 60.8 \%$, and $55.8 \%$ respectively) of the studied nurses gave incomplete correct answer about guidelines must be followed when acupuncture, main patient safety standards inside the center, common causes of medical risks occurring inside the center and capabilities of the health center to maintain patient safety, and definition of safety in health care respectively.

Finally, more than one third $(36.7 \%$ and $34.2 \%$ ) of studied nurses gave don't know answer about medication errors that cause an unexpected error or harm to the patient and Incident report strategy of raising an unexpected event that is examined for the patients. Also, one quarter $(25.5 \%)$ of them didn't know answer about common causes of medical risks occurring inside the center.
Table 3: represents percent distribution of the studied nurses according to their total knowledge level toward client safety in $\mathrm{MCH}$ center. It reported that the mean and standard deviation of total knowledge score were 27.095.489 with rang (17-40). The table showed that more than one third (40.8\%) of them had good total knowledge score while more than one quarter $(31.7 \%)$ of them had poor total knowledge score toward client safety in $\mathrm{MCH}$ center, slightly more than one quarter $(27.5 \%)$ of them had fair total knowledge score toward patient safety.

Figure 1: represents mean scores of the attitude domains of the studied nurses towards patient safety. The figure showed that the mean score of safety climate domain was $11,32 \%$. While the mean score of the teamwork climate and client satisfaction domain were $9.72 \%$ and $9.12 \%$ respectively. Also the mean score of the work condition in the center and perception of primary health care center were $6.67 \%$ and $6.6 \%$ respectively, while the mean score of stress perception domain was $3.69 \%$

Table 4 , represents percent distribution of the studied nurses according to their nursing total attitude score towards patient safety, It showed that, the majority $(89.2 \%)$ of the studied nurses have a positive attitude, while the minority of them ( 
$10.8 \%$ ) have negative attitude toward patient safety with mean (47.117.168).

Table 5: represents percent distribution of the studied nurses according to their nursing practice toward maintaining patient safety in antenatal clinics based on observation. The table showed that, all of the studied nurses uses disposable syringes during IM $\backslash I V$ injection, and recording specific information completely. It was also found that the majority $(83.3 \%)$ of them incompletely communicates clearly to ensure patient safety, wash hands before procedure and wearing gloves.

In the same table it can be seen that, $38.9 \%$ and $33.3 \%$ of studied nurses didn't perform practices related to uses hand rub for hand washing with water and soap/alcohol and checking cleanliness of the examination room respectively. Only $16.7 \%$ and $11.1 \%$ of nurses didn't explains procedure to women and rational for each step and prepares equipment respectively.

Table 6: reveals assessment of the studied nurses according to their nursing practice toward maintaining patient safety in family planning counseling clinic. The table showed that, most $(95.5 \%)$ of the studied nurses uses disposable syringes during IM IV injection completely and more than three quarters $86.4 \%$ and $81.8 \%$ of them completely use client record and explains methods of family planning about how to use it and sterilizes family planning equipment respectively).

On the other hands the table also illustrated that more than half (59. 1\%)of the studied nurses incompletely performed practices related to hand washing before procedure and wearing gloves and $(50.0 \%)$ of them incompletely demonstrates good counseling skills as introducing themselves to clients. More than one third $(36.4 \%)$ of them didn't perform hand rub for handwashing or water and soap/alcohol.

Table 7: represents assessment of the studied nurses according to their nursing practice toward maintaining patient safety in vaccination clinics. The table showed that, all of the studied nurses completely perform practice regarding checking age indications for the vaccines, administering vaccines to the correct age groups, and put used needles and syringes immediately in a sharps container following administration. Also the majority $(95.8 \%$ and $91.7 \%$ ) of nurses completely perform practices regarding administering vaccines using the correct route per manufacturer instructions, identifying injection site correctly and identifies newborn and their parent on the card respectively.

The table also illustrated that, more than half $(54.2 \%)$ of the studied nurses were in completely perform practices regarding using proper hygiene techniques to clean 
hands before vaccine administration, between patients, and anytime when hands become soiled. Only one quarter $(25 \%)$ of the studied nurses in completely perform practices regarding screening the client for contraindications and precautions for the specific vaccine(s) in use before receiving that vaccine(s).

Table 8: reveals assessment of the studied nurses according to their nursing practice toward maintaining patient safety in child clinics. The table showed that, all of studied nurses perform practices completely regarding identifying newborn and their parent on the card, and recording all data about diseased child diagnosis, treatment and referral system. While more than two thirds $(66.7 \%)$ of studied the nurses incompletely perform practices regarding wash their hands before any examination to newborn respectively. Only $13.3 \%$ and $6.7 \%$ of the studied nurses didn't perform practices regarding the nurse prepare safe place to conduct follow up examination and nurse. In the same table it can be seen that all of the studied nurses (100\%) completely perform practices regarding recording all data about diseased child diagnosis, treatment and referral system. As well as, the majority (94.4\%)of them completely perform practices regarding identifying child attending outpatient clinic on his card.
Table 9 : represents assessment of the studied nurses according to their nursing practice toward maintaining patient safety in dental clinics The table showed that, more than three quarters ( $88.9 \%$ and $83.3 \%$ ) of the studied nurses completely perform practices related to making sure that the dentist known that women was pregnant, and instructed parents to check dentist development for their children frequently, educated women and encouraged behaviors that support good oral health: brushing teeth twice daily with fluoridated toothpaste, especially before bedtime, and flossing daily, instructed parents to check dentist development for their children frequently and inspected and tested all equipment used in patient care on regular basis and according to manufacturer's specifications, encouraged all women at the first prenatal visit to schedule a dental examination and identification of patient done respectively.

Table 10: represents assessment of the studied nurses according to their nursing practice toward maintaining patient safety in emergency clinics. The table showed that, all of studied nurses (100\%) completely performed practices related to identifying patient before giving any medication, identifying potential medication risks are Look-alike, soundalike (LASA)and ensured that emergency 
drugs, devices, equipment and supplies must be available for immediate use in the urgent care area for treating lifethreatening conditions respectively. Moreover, $(100 \%)$ one hundred percent of them didn't perform hand hygiene technique to prevent health care-associated infection.

Table 11: represents assessment of the studied nurses according to their nursing total practice level toward maintaining patient safety in the studied different clinics. The table showed that, the majority (95.8\%, 90.9\%, 86.7\% and $80.0 \%$ ) of studied nurses' total practice levels were satisfactory in vaccination clinic, family planning clinic, follow up newborn clinic and emergency clinic respectively. While more than three quarters $(83.3 \%)$ of the studied nurses their total practice level was unsatisfactory in dental clinic and half of them $(50 \%)$ their total practices level were unsatisfactory in child out-patient clinic.

Table 12: represents correlations between the knowledge score of the studied nurses about maintaining patient safety, their attitude and practice scores among the maternal and child health care centers. The table showed that, there was a positive non-significant correlation between knowledge score level and attitude score level (r: 0.059 p: 0.521). In the other hand there was negative non-significant correlation between total knowledge score and total practical level in antenatal clinic, family planning clinic, child out-patient clinic, dental clinic and emergency clinic $r$ $(-0.024, \quad 0.061, \quad 0.218, \quad 0.242$ and0.427 respectively). While, there is a positive non-significant correlation between total knowledge score and total practical level in vaccination clinic, follow up newborn clinic (r: 0.189, o.113 p: o.688)

Table 13: reveals relationship between socio demographic characteristics of the studied nurses and their total knowledge and attitude mean scores about maintaining patient safety. This table showed that, the maximum knowledge mean score were found it in among who were aged from(40-<50) (27.825.222), who had rural residence (27.675.688), who had Bachelor degree qualification ( 29.003.367) and who had years of experience $(20-<30)$ (28.405.147) There is statistically significant relationship found between total knowledge score and all items of the studied nurses sociodemographic characteristics (P0.05) except with years of experience $(\mathrm{p}=0.416)$

The table showed also that, maximum attitude mean score were found in who aged from $(40-<50)$ ( 47.576.258), who had rural residence (49.504.2,) who had Bachelor degree qualification(49.256.702) who had years of experience from (30-< 
40)( 48.735.366) with (p: $\left.0.000^{*}\right)$ There is statistically significant relationship between total attitude score and all items of the studied nurses sociodemographic characteristics(P0.05). except with age (P:o,333) 
Table (I): Assessment of the studied nurses according to their socio-demographic characteristics

\begin{tabular}{|c|c|c|}
\hline \multirow{2}{*}{\begin{tabular}{|r} 
Characteristics \\
Age (in years)
\end{tabular}} & \multicolumn{2}{|c|}{$\begin{array}{l}\text { The studied nurses } \\
\qquad(\mathrm{N}=\mathbf{1 2 0})\end{array}$} \\
\hline & & \\
\hline$-\quad(30-<40)$ & 18 & 15.0 \\
\hline$-\quad(40-<50)$ & 60 & 50.0 \\
\hline$-\quad \geq 50$ & 42 & 35.0 \\
\hline Range & \multirow{2}{*}{\multicolumn{2}{|c|}{$\begin{array}{c}(30-59) \\
46.316 .573\end{array}$}} \\
\hline MeanSD & & \\
\hline \multicolumn{3}{|l|}{ - Gender } \\
\hline - Female & 120 & 100.0 \\
\hline - $\quad$ Place of residence & & \\
\hline - $\quad$ Rural & 18 & 15.0 \\
\hline - Urban & 102 & 85.0 \\
\hline \multicolumn{3}{|l|}{ Qualification } \\
\hline - $\quad$ Technician nursing (3 years) & 105 & 87.5 \\
\hline - $\quad$ Technician nursing (5 years) & 11 & 9.2 \\
\hline - Bachelor & 4 & 3.3 \\
\hline \multicolumn{3}{|l|}{ Years of experience (in years) } \\
\hline$-\quad(10-<20)$ & 17 & 14.2 \\
\hline$-\quad(20-<30)$ & 57 & 47.5 \\
\hline$-\quad(30-\leq 40)$ & 46 & 38.3 \\
\hline Range & \multirow{2}{*}{\multicolumn{2}{|c|}{$\begin{array}{c}(10-40) \\
26.416 .906\end{array}$}} \\
\hline MeanSD & & \\
\hline Clinics & & \\
\hline - Antenatal clinic. & 18 & 15.0 \\
\hline - $\quad$ Family planning clinic. & 22 & 18.3 \\
\hline - Vaccination clinic. & 24 & 20.0 \\
\hline - Follow up newborn clinic. & 15 & 12.5 \\
\hline - Child out-patient clinic. & 18 & 15.0 \\
\hline - Dental clinic. & 18 & 15.0 \\
\hline - Emergency clinic & 5 & 4.2 \\
\hline
\end{tabular}


Table (2) Assessment of the studied nurses according to their knowledge toward client safety in MCH center

\begin{tabular}{|c|c|c|c|c|c|c|}
\hline \multirow{3}{*}{ Knowledge items } & \multicolumn{6}{|c|}{ The studied nurses $(\mathrm{N}=120)$} \\
\hline & \multicolumn{2}{|c|}{$\begin{array}{l}\text { Don't } \\
\text { know }\end{array}$} & \multicolumn{2}{|c|}{$\begin{array}{c}\text { Incomplete } \\
\text { correct }\end{array}$} & \multicolumn{2}{|c|}{$\begin{array}{c}\text { Complete } \\
\text { correct }\end{array}$} \\
\hline & $\mathbf{N}$ & $\%$ & $\mathbf{N}$ & $\%$ & $\mathbf{N}$ & $\%$ \\
\hline - $\quad$ Definition of safety & 1 & 0.8 & 56 & 46.7 & 63 & 52.5 \\
\hline - Definition of safety in health care & 1 & 0.8 & 69 & 57.5 & 50 & 41.7 \\
\hline - Definition of the safety climate & 4 & 3.3 & 67 & 55.8 & 49 & 0.8 \\
\hline $\begin{array}{l}\text { Benefit from the application of patient safety } \\
\text { in MCH centers }\end{array}$ & 0 & 0.0 & 63 & 52.5 & 57 & 47.5 \\
\hline $\begin{array}{l}\text { Means of improving nursing skills about } \\
\text { patient safety }\end{array}$ & 1 & 0.8 & 52 & 43.3 & 67 & 55.8 \\
\hline $\begin{array}{l}\text { Common causes of medical risks occurring } \\
\text { inside the center }\end{array}$ & 31 & 25.8 & 73 & 60.8 & 16 & 13.3 \\
\hline - Main patient safety standards inside the center & 1 & 0.8 & 76 & 63.3 & 43 & 35.8 \\
\hline $\begin{array}{l}\text { - Capabilities of the health center to maintain } \\
\text { patient safety }\end{array}$ & 3 & 2.5 & 73 & 60.8 & 44 & 36.7 \\
\hline - Nursing plan to deal with health risks & 5 & 4.2 & 64 & 53.3 & 51 & 42.5 \\
\hline $\begin{array}{l}\text { Policies reinforce activities of patient safety } \\
\text { on the center }\end{array}$ & 7 & 5.8 & 56 & 46.7 & 57 & 47.5 \\
\hline $\begin{array}{l}\text { Principles that nursing must adhere to in } \\
\text { order to maintain patient safety inside the } \\
\text { clinics }\end{array}$ & 2 & 1.7 & 56 & 46.7 & 62 & 51.7 \\
\hline $\begin{array}{l}\text { Environmental practices in the center to } \\
\text { maintain patient safety }\end{array}$ & 1 & 0.8 & 48 & 40.0 & 71 & 59.2 \\
\hline $\begin{array}{l}\text { Damages suffered by health service recipients } \\
\text { from the absence of safe environment }\end{array}$ & 37 & 30.8 & 55 & 45.8 & 28 & 23.3 \\
\hline $\begin{array}{l}\text { Instructions that must be followed up by } \\
\text { nursing staff to prevent the spread of infection } \\
\text { in the clinics of the center }\end{array}$ & 0 & 0.0 & 30 & 25.0 & 90 & 75.0 \\
\hline $\begin{array}{l}\text { Nursing practices to prevent recipient from } \\
\text { falling risks in the center }\end{array}$ & 1 & 0.8 & 37 & 30.8 & 82 & 68.3 \\
\hline $\begin{array}{l}\text { Safety box specifications for the disposable of } \\
\text { pins and sharp instruments in the clinics }\end{array}$ & 1 & 0.8 & 35 & 29.2 & 84 & 70.0 \\
\hline \begin{tabular}{|lllll} 
Guidelines must be followed when \\
acupuncture
\end{tabular} & 0 & 0.0 & 79 & 65.8 & 41 & 34.2 \\
\hline $\begin{array}{l}\text { Dental clinics provide basic services } \\
\text { pregnant women during follow-up and } \\
\text { children visits }\end{array}$ & 7 & 5.8 & 69 & $\mathbf{5 7 . 5}$ & 44 & 36.7 \\
\hline $\begin{array}{l}\text { Medication errors that cause an unexpected } \\
\text { error or harm to the patient }\end{array}$ & 44 & 36.7 & 55 & 45.8 & 21 & 17.5 \\
\hline $\begin{array}{l}\text { Incident report strategy of raising an } \\
\text { unexpected event that is examined for the } \\
\text { patients }\end{array}$ & 41 & 34.2 & 60 & 50.0 & 19 & 15.8 \\
\hline
\end{tabular}


Table 3: Percent distribution of the studied nurses according to their Total knowledge level toward client safety in MCH center

\begin{tabular}{|c|c|c|}
\hline \multicolumn{1}{|c|}{$\begin{array}{c}\text { Total } \\
\text { knowledge } \\
\text { level }\end{array}$} & \multicolumn{2}{|l|}{$\begin{array}{l}\text { The studied } \\
(\mathbf{N = 1 2 0})\end{array}$} \\
\hline & $\mathbf{N}$ & \%urses \\
\hline - Poor & 38 & 31.7 \\
$-\quad$ Fair & 33 & 27.5 \\
$-\quad$ Good & 49 & 40.8 \\
\hline Range & $\mathbf{( 1 7 - 4 0 )}$ \\
Mean SD & $\mathbf{2 7 . 0 9 5 . 4 8 9}$ \\
\hline
\end{tabular}

$<60 \%$ Poor

$(60-70) \%$ Fair $\quad>70 \%$ Good.

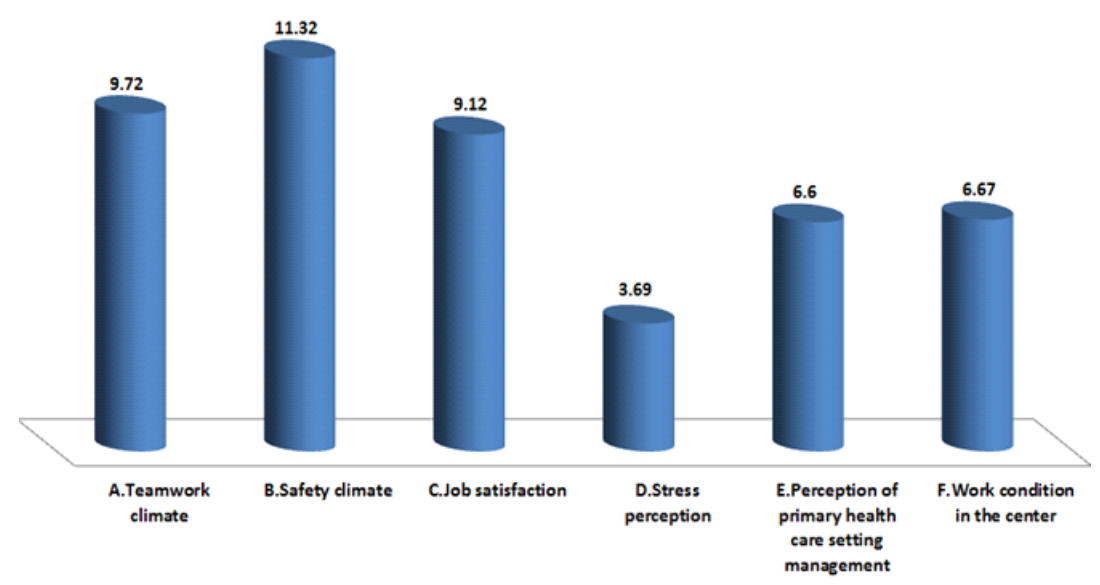

Figure1: Mean scores of the attitude domains of the studied nurses towards patient safety

Table 4: Percent distribution of the studied nurses according to their total attitude level towards patient safety

\begin{tabular}{|l|l|l|}
\hline $\begin{array}{l}\text { Total } \\
\text { attitude } \\
\text { level }\end{array}$ & \multicolumn{2}{|l|}{$\begin{array}{l}\text { The studied nurses } \\
(\mathbf{N = 1 2 0})\end{array}$} \\
\cline { 2 - 3 } & $\mathbf{N}$ & $\%$ \\
\hline$-\quad$ Negative attitude $<70 \%$ & 13 & 10.8 \\
$\quad-\quad$ Positive attitude $>70 \%$ & 107 & 89.2 \\
\hline Range & $\mathbf{2 1 - 6 0 )}$ \\
Mean SD & $\mathbf{4 7 . 1 1 7 . 1 6 8}$ \\
\hline
\end{tabular}

$<70 \%$ Negative attitude $\quad \geq 70 \%$ Positive attitude 
Table 5: Assessment of the studied nurses according to their nursing practice toward maintaining patient safety in antenatal clinic

\begin{tabular}{|c|c|c|c|c|c|c|}
\hline \multirow{3}{*}{ Antenatal clinic } & \multicolumn{6}{|c|}{ The studied nurses $(\mathrm{N}=18)$} \\
\hline & \multicolumn{2}{|c|}{$\begin{array}{c}\text { Not } \\
\text { done }\end{array}$} & \multicolumn{2}{|c|}{$\begin{array}{c}\text { Incomplete } \\
\text { done }\end{array}$} & \multicolumn{2}{|c|}{$\begin{array}{l}\text { Complete } \\
\text { done }\end{array}$} \\
\hline & $\mathbf{N}$ & $\%$ & $\mathbf{N}$ & $\%$ & $\mathbf{N}$ & $\%$ \\
\hline - $\quad$ Greets the mother & 0 & 0.0 & 7 & 38.9 & 11 & 61.1 \\
\hline - $\quad$ prepares place and adequate light room & 0 & 0.0 & 9 & 50.0 & 9 & 50.0 \\
\hline - Prepares equipment & 2 & 11.1 & 3 & 16.7 & 13 & 72.2 \\
\hline - $\quad$ Assures client confidentiality & 0 & 0.0 & 7 & 38.9 & 11 & 61.1 \\
\hline - $\quad$ treats client with dignity and respect & 1 & 5.6 & 6 & 33.3 & 11 & 61.1 \\
\hline $\begin{array}{l}\text { - explains procedure to women and rational for } \\
\text { each step }\end{array}$ & 3 & 16.7 & 10 & 55.6 & 5 & 27.8 \\
\hline - $\quad$ communicates clearly to ensure patient safety & 0 & 0.0 & 15 & 83.3 & 3 & 16.7 \\
\hline $\begin{array}{ll}\text { washes hands before procedure and wear } \\
\text { gloves }\end{array}$ & 0 & 0.0 & 15 & 83.3 & 3 & 16.7 \\
\hline $\begin{array}{l}\text { Uses hand rub for handwashing with water } \\
\text { and soap/alcohol. }\end{array}$ & 7 & 38.9 & 11 & 61.1 & 0 & 0.0 \\
\hline - checks cleanliness of the examination room & 6 & 33.3 & 5 & 27.8 & 7 & 38.9 \\
\hline $\begin{array}{lllll}\text { - Uses disposable } & \text { syringes } & \text { during } & \text { IM } \backslash I V \\
\text { injection }\end{array}$ & 0 & 0.0 & 0 & 0.0 & 18 & 100.0 \\
\hline - The nurse is recording specific information & 0 & 0.0 & 0 & 0.0 & 18 & 100.0 \\
\hline - $\quad$ The nurse sets date for next follow-up visit & 0 & 0.0 & 4 & 22.2 & 14 & 77.8 \\
\hline
\end{tabular}

Table 6: Assessment of the studied nurses according to their nursing practice toward maintaining patient safety in family planning counseling clinic

\begin{tabular}{|c|c|c|c|c|c|c|}
\hline \multirow{3}{*}{$\begin{array}{l}\text { Family Planning } \\
\text { Counseling clinic }\end{array}$} & \multicolumn{6}{|c|}{ The studied nurses $(\mathrm{N}=22)$} \\
\hline & \multicolumn{2}{|c|}{$\begin{array}{l}\text { Not } \\
\text { done }\end{array}$} & \multicolumn{2}{|c|}{$\begin{array}{l}\text { Incomplete } \\
\text { done }\end{array}$} & \multicolumn{2}{|c|}{$\begin{array}{l}\text { Complete } \\
\text { done }\end{array}$} \\
\hline & $\mathbf{N}$ & $\%$ & $\mathbf{N}$ & $\%$ & $\mathbf{N}$ & $\%$ \\
\hline - greets the mother & 0 & 0.0 & 8 & 36.4 & 14 & 63.6 \\
\hline - $\quad$ prepares place and adequate light room & 0 & 0.0 & 7 & 31.8 & 15 & 68.2 \\
\hline - prepares equipment & 2 & 9.1 & 4 & 18.2 & 16 & 72.7 \\
\hline - $\quad$ assures client confidentiality & 0 & 0.0 & 9 & 40.9 & 13 & 59.1 \\
\hline - $\quad$ treats client with dignity and respect & 0 & 0.0 & 5 & 22.7 & 17 & 77.3 \\
\hline $\begin{array}{l}\text { - Demonstrates good counseling skills as } \\
\text { introducing themselves to clients }\end{array}$ & 1 & 4.5 & 11 & 50.0 & 10 & 45.5 \\
\hline $\begin{array}{ll}\text { - } & \text { Recognizes/identifies contraindications } \\
\text { consistent with guidelines }\end{array}$ & 2 & 9.1 & 6 & 27.3 & 14 & 63.6 \\
\hline $\begin{array}{l}\text { - checks cleanliness of the examination } \\
\text { room }\end{array}$ & 1 & 4.5 & 10 & 45.5 & 11 & 50.0 \\
\hline $\begin{array}{l}\text { - wash hands before procedure and wear } \\
\text { gloves. }\end{array}$ & 1 & 4.5 & 13 & 59.1 & 8 & 36.4 \\
\hline $\begin{array}{l}\text { - Uses hand rub for hand-washing or water } \\
\text { and soap/alcohol. }\end{array}$ & 8 & 36.4 & 6 & 27.3 & 8 & 36.4 \\
\hline $\begin{array}{l}\text { - Explains methods of family planning } \\
\text { about how to use it. }\end{array}$ & 1 & 4.5 & 2 & 9.1 & 19 & 86.4 \\
\hline - $\quad$ Sterilizes family planning equipment & 0 & 0.0 & 4 & 18.2 & 18 & 81.8 \\
\hline $\begin{array}{ll}\text { - Uses disposable syringes during IM } \backslash I V \\
\text { injection }\end{array}$ & 1 & 4.5 & 0 & 0.0 & 21 & 95.5 \\
\hline - Uses visual aids & 1 & 4.5 & 6 & 27.3 & 15 & 68.2 \\
\hline - Uses client record & 0 & 0.0 & 1 & 4.5 & 21 & 95.5 \\
\hline
\end{tabular}


Table 7: Assessment of the studied nurses according to their nursing practice toward maintaining patient safety in vaccination clinics

\begin{tabular}{|c|c|c|c|c|c|c|}
\hline \multirow{3}{*}{ Vaccination Clinics } & \multicolumn{6}{|c|}{ The studied nurses $(\mathrm{N}=24)$} \\
\hline & \multicolumn{2}{|c|}{$\begin{array}{l}\text { Not } \\
\text { done }\end{array}$} & \multicolumn{2}{|c|}{$\begin{array}{l}\text { Incomplete } \\
\text { done }\end{array}$} & \multicolumn{2}{|c|}{$\begin{array}{l}\text { Complete } \\
\text { done }\end{array}$} \\
\hline & $\mathbf{N}$ & $\%$ & $\mathbf{N}$ & $\%$ & $\mathbf{N}$ & $\%$ \\
\hline Identifies newborn and their parent on the card & 0 & 0.0 & 2 & 8.3 & 22 & 91.7 \\
\hline $\begin{array}{l}\text { The nurse is administering vaccines reviewed } \\
\text { vaccine manufacturer instructions for } \\
\text { administration before vaccination }\end{array}$ & 0 & 0.0 & 4 & 16.7 & 20 & 83.3 \\
\hline $\begin{array}{l}\text { The nurse is using proper hygiene techniques to } \\
\text { clean hands before vaccine administration, } \\
\text { between patients, and anytime when hands } \\
\text { become soiled. }\end{array}$ & 0 & 0.0 & 13 & 54.2 & 11 & 45.8 \\
\hline $\begin{array}{l}\text { The nurse prepared vaccine in a clean, } \\
\text { designated medication area, away from any } \\
\text { potentially contaminated items. }\end{array}$ & 1 & 4.2 & 10 & 41.7 & 13 & 54.2 \\
\hline Prepared vaccines at the time of administration. & 2 & 8.3 & 2 & 8.3 & 20 & 83.3 \\
\hline $\begin{array}{l}\text { Screening the client for contraindications and } \\
\text { precautions for the specific vaccine(s) in use } \\
\text { before receiving that vaccine(s). }\end{array}$ & 2 & 8.3 & 6 & 25.0 & 16 & 66.7 \\
\hline $\begin{array}{l}\text { The nurse is triple-checking labels, contents, and } \\
\text { expiration dates or beyond use dates before } \\
\text { administering vaccine. }\end{array}$ & 0 & 0.0 & 5 & 20.8 & 19 & 79.2 \\
\hline $\begin{array}{l}\text { The nurse is administering vaccines using the } \\
\text { correct route per manufacturer instructions. }\end{array}$ & 0 & 0.0 & 1 & 4.2 & 23 & 95.8 \\
\hline $\begin{array}{l}\text { Staff has checked age indications for the } \\
\text { vaccines and is administering vaccines to the } \\
\text { correct age groups }\end{array}$ & 0 & 0.0 & 0 & 0.0 & 24 & 100.0 \\
\hline - Identifying injection site correctly & 0 & 0.0 & 1 & 4.2 & 23 & 95.8 \\
\hline $\begin{array}{l}\text { The nurse put used needles and syringes } \\
\text { immediately in a sharps container following } \\
\text { administration. }\end{array}$ & 0 & 0.0 & 0 & 0.0 & 24 & 100.0 \\
\hline $\begin{array}{l}\text { The nurse instruct mother of the child regarding } \\
\text { given vaccine and how to deal with the site of } \\
\text { vaccine taking }\end{array}$ & 0 & 0.0 & 5 & 20.8 & 19 & 79.2 \\
\hline
\end{tabular}


Table 8: Assessment of the studied nurses according to their nursing practice toward maintaining patient safety in child clinics

\begin{tabular}{|c|c|c|c|c|c|c|}
\hline \multirow{3}{*}{ Child clinics } & \multicolumn{6}{|c|}{ The studied nurses } \\
\hline & \multicolumn{2}{|c|}{$\begin{array}{l}\text { Not } \\
\text { done }\end{array}$} & \multicolumn{2}{|c|}{$\begin{array}{l}\text { Incomplete } \\
\text { done }\end{array}$} & \multicolumn{2}{|c|}{$\begin{array}{l}\text { Complete } \\
\text { done }\end{array}$} \\
\hline & $\mathbf{N}$ & $\%$ & $\mathbf{N}$ & $\%$ & $\mathbf{N}$ & $\%$ \\
\hline \multicolumn{7}{|l|}{ A-Follow up clinic $(\mathrm{N}=15)$} \\
\hline $\begin{array}{l}\text { - Nurse identify newborn and their parent on } \\
\text { the card }\end{array}$ & 0 & 0.0 & 0 & 0.0 & 15 & 100.0 \\
\hline $\begin{array}{ll}\text { - } & \text { Nurse take full clinical examination of the } \\
& \text { newborn }\end{array}$ & 0 & 0.0 & 4 & 26.7 & 11 & 73.3 \\
\hline $\begin{array}{ll}- & \text { Nurse wash hands before any examination } \\
& \text { to newborn }\end{array}$ & 1 & 6.7 & 10 & 66.7 & 4 & 26.7 \\
\hline $\begin{array}{ll}\text { - } & \text { Nurse record all data about newborn on his } \\
& \text { Card }\end{array}$ & 0 & 0.0 & 2 & 13.3 & 13 & 86.7 \\
\hline $\begin{array}{l}\text { - Nurse prepare safe place to conduct follow } \\
\text { up examination }\end{array}$ & 2 & 13.3 & 4 & 26.7 & 9 & 60.0 \\
\hline \multicolumn{7}{|l|}{ B- Outpatient clinic $(n=18)$} \\
\hline $\begin{array}{l}\text { - The children are treated with respect and } \\
\text { patience }\end{array}$ & 0 & 0.0 & 10 & 55.6 & 8 & 44.4 \\
\hline - $\quad$ All staff are relaxed and flexible & 6 & 33.3 & 8 & 44.4 & 4 & 22.2 \\
\hline $\begin{array}{l}\text { - The nurse prepares equipment before any } \\
\text { examination }\end{array}$ & 0 & 0.0 & 4 & 22.2 & 14 & 77.8 \\
\hline $\begin{array}{l}\text { - The nurse identify child attending outpatient } \\
\text { clinic on his card. }\end{array}$ & 0 & 0.0 & 1 & 5.6 & 17 & 94.4 \\
\hline $\begin{array}{l}\text { - The nurse will maintain high standards of } \\
\text { hygiene by: } \\
\text { - wash hand before conducting any procedure } \\
\text { to the child rubbing hand with alcohol } \\
\text { between cases }\end{array}$ & 0 & 0.0 & 12 & 66.7 & 6 & 33.3 \\
\hline - $\quad$ maintain well ventilated clinic & 0 & 0.0 & 15 & 83.3 & 3 & 16.7 \\
\hline $\begin{array}{l}\text { - The nurse records all data about diseased } \\
\text { child diagnosis, treatment and referral } \\
\text { system. }\end{array}$ & 0 & 0.0 & 0 & 0.0 & 18 & 100.0 \\
\hline $\begin{array}{l}\text { - All cleaning products are inaccessible to } \\
\text { children }\end{array}$ & 4 & 22.2 & 14 & 77.8 & 0 & 0.0 \\
\hline
\end{tabular}


Table 9 : Assessment of the studied nurses according to their nursing practice toward maintaining patient safety in dental clinics

\begin{tabular}{|c|c|c|c|c|c|c|}
\hline \multirow{3}{*}{ Dental clinic } & \multicolumn{6}{|c|}{ The studied nurses $(\mathrm{N}=18)$} \\
\hline & \multicolumn{2}{|c|}{$\begin{array}{c}\text { Not } \\
\text { done }\end{array}$} & \multicolumn{2}{|c|}{$\begin{array}{l}\text { Incomplete } \\
\text { done }\end{array}$} & \multicolumn{2}{|c|}{$\begin{array}{l}\text { Complete } \\
\text { done }\end{array}$} \\
\hline & $\mathbf{N}$ & $\%$ & $\mathbf{N}$ & $\%$ & $\mathbf{N}$ & $\%$ \\
\hline $\begin{array}{l}\text { - The nurse inspected and tested all equipment used } \\
\text { in patient care on regular basis and according to } \\
\text { manufacturer's specifications. }\end{array}$ & 0 & 0.0 & 3 & 16.7 & 15 & 83.3 \\
\hline $\begin{array}{l}\text { - The nurse must ensure good ventilation dental } \\
\text { procedure room. }\end{array}$ & 3 & 16.7 & 9 & 50.0 & 6 & 33.3 \\
\hline - Assures client of confidentiality. & 3 & 16.7 & 10 & 55.6 & 5 & 27.8 \\
\hline $\begin{array}{l}\text { - Checks that dental needle preferably not be used in } \\
\text { more than two insertion on same patient. }\end{array}$ & 6 & 33.3 & 9 & 50.0 & 3 & 16.7 \\
\hline $\begin{array}{l}\text { - Make sure your dentist knows that women are } \\
\text { pregnant. }\end{array}$ & 0 & 0.0 & 2 & 11.1 & 16 & 88.9 \\
\hline $\begin{array}{l}\text { Avoided routine x-rays in pregnancy women, but it } \\
\text { may be necessary if there is a problem or an } \\
\text { emergency. }\end{array}$ & 1 & 5.6 & 5 & 27.8 & 12 & 66.7 \\
\hline $\begin{array}{l}\text { - Checks that dental trays washed and sanitized after } \\
\text { each patient. }\end{array}$ & 3 & 16.7 & 8 & 44.4 & 7 & 38.9 \\
\hline $\begin{array}{l}\text { Uses single-dose (single-use) vials, ampules, and } \\
\text { bags or bottles of intravenous solutions are used } \\
\text { for only one patient. }\end{array}$ & 4 & 22.2 & 12 & 66.7 & 2 & 11.1 \\
\hline $\begin{array}{l}\text { - Ensures single-use devices are discarded after one } \\
\text { use and not used for more than one patient. }\end{array}$ & 3 & 16.7 & 10 & 55.6 & 5 & 27.8 \\
\hline $\begin{array}{l}\text { - The nurse ensure that waterlines flushed after each } \\
\text { patient. }\end{array}$ & 12 & 66.7 & 5 & 27.8 & 1 & 5.6 \\
\hline $\begin{array}{l}\text { - The nurse change dental chair head rest cap and } \\
\text { patient apron after each patient. }\end{array}$ & 18 & 100.0 & 0 & 0.0 & 0 & 0.0 \\
\hline $\begin{array}{l}\text { The nurse encourage all women at the first } \\
\text { prenatal visit to schedule a dental examination. }\end{array}$ & 1 & 5.6 & 2 & 11.1 & 15 & 83.3 \\
\hline $\begin{array}{l}\text { - The nurse instructs parents to check dentist } \\
\text { development for their children frequently }\end{array}$ & 0 & 0.0 & 2 & 11.1 & 16 & 88.9 \\
\hline $\begin{array}{l}\text { - The nurse educates women and encourage } \\
\text { behaviors that support good oral health: brushing } \\
\text { teeth twice daily with fluoridated toothpaste, } \\
\text { especially before bedtime, and flossing daily }\end{array}$ & 0 & 0.0 & 2 & 11.1 & 16 & 88.9 \\
\hline $\begin{array}{l}\text { The nurse should check: } \\
\text { - Consent form signed }\end{array}$ & 1 & 5.6 & 4 & 22.2 & 13 & 72.2 \\
\hline - Patient case notes/x-ray checked & 4 & 22.2 & 5 & 27.8 & 9 & 50.0 \\
\hline - Identification of patient done & 0 & 0.0 & 3 & 16.7 & 15 & 83.3 \\
\hline - Allergies checked & 10 & 55.6 & 6 & 33.3 & 2 & 11.1 \\
\hline - Pre-medication given & 8 & 44.4 & 8 & 44.4 & 2 & 11.1 \\
\hline - check anti-coagulant used & 16 & 88.9 & 2 & 11.1 & 0 & 0.0 \\
\hline
\end{tabular}


Table 10 : Assessment of the studied nurses according to their practice toward maintaining patient safety in emergency clinics

\begin{tabular}{|c|c|c|c|c|c|c|}
\hline \multirow{3}{*}{ Emergency clinic } & \multicolumn{6}{|c|}{ The studied nurses $(\mathrm{N}=5)$} \\
\hline & \multicolumn{2}{|c|}{$\begin{array}{l}\text { Not } \\
\text { done }\end{array}$} & \multicolumn{2}{|c|}{$\begin{array}{l}\text { Incomplete } \\
\text { done }\end{array}$} & \multicolumn{2}{|c|}{$\begin{array}{l}\text { Complete } \\
\text { done }\end{array}$} \\
\hline & $\mathbf{N}$ & $\%$ & $\mathbf{N}$ & $\%$ & $\mathbf{N}$ & $\%$ \\
\hline \begin{tabular}{|lll} 
- & $\begin{array}{l}\text { Identifies patient before given any } \\
\text { medication. }\end{array}$
\end{tabular} & 0 & 0.0 & 0 & 0.0 & 5 & 100.0 \\
\hline - $\quad$ Assures client of confidentiality & 0 & 0.0 & 2 & 40.0 & 3 & 60.0 \\
\hline $\begin{array}{l}\text { The nurse ensures that emergency drugs, } \\
\text { devices, equipment and supplies must be } \\
\text { available for immediate use in the Urgent } \\
\text { Care area for treating life-threatening } \\
\text { conditions. }\end{array}$ & 0 & 0.0 & 0 & 0.0 & 5 & 100.0 \\
\hline $\begin{array}{l}\text { Prevents patient falls by providing well- } \\
\text { designed patient rooms and bathrooms. }\end{array}$ & 0 & 0.0 & 3 & 60.0 & 2 & 40.0 \\
\hline $\begin{array}{l}\text { The nurse has decentralized stations that } \\
\text { allow easy access to patients. }\end{array}$ & 0 & 0.0 & 1 & 20.0 & 4 & 80.0 \\
\hline $\begin{array}{l}\text { - The nurse has daily inspection of the } \\
\text { provision of stretchers / trolleys. }\end{array}$ & 0 & 0.0 & 1 & 20.0 & 4 & 80.0 \\
\hline $\begin{array}{l}\text { - The nurse increase provision of transport } \\
\text { equipment. }\end{array}$ & 1 & 20.0 & 2 & 40.0 & 2 & 40.0 \\
\hline $\begin{array}{ll}\text { - Identified potential medication risks are } \\
\text { Look-alike, sound-alike (LASA). }\end{array}$ & 0 & 0.0 & 0 & 0.0 & 5 & 100.0 \\
\hline $\begin{array}{l}\text { - Uses hand hygiene technique to prevent } \\
\text { health care-associated infection }\end{array}$ & 5 & 100.0 & 0 & 0.0 & 0 & 0.0 \\
\hline \begin{tabular}{|lll}
- & Observes continuously progress of \\
emergency patient to avoid overlapping
\end{tabular} & 0 & 0.0 & 3 & 60.0 & 2 & 40.0 \\
\hline
\end{tabular}

Table 11: Assessment of the studied nurses according to their nursing total practice level toward maintaining patient safety in the studied different clinics

\begin{tabular}{|l|c|c|c|c|}
\hline \multirow{2}{*}{ Clinics } & \multicolumn{3}{|l|}{$\begin{array}{l}\text { Total practice level of } \\
\text { the studied nurses }\end{array}$} \\
\cline { 2 - 6 } & Unsatisfactory & \multicolumn{2}{l|}{ Satisfactory } \\
\cline { 2 - 5 } & $\mathbf{N}$ & $\mathbf{\%}$ & $\mathbf{N}$ & $\mathbf{\%}$ \\
\hline 1.Antenatal clinic $(\mathrm{n}=18)$ & 8 & 44.4 & 10 & 55.6 \\
\hline 2.Family planning clinic $(\mathrm{n}=22)$ & 2 & 9.1 & 20 & 90.9 \\
\hline 3.Vaccination clinic $(\mathrm{n}=24)$ & 1 & 4.2 & 23 & 95.8 \\
\hline 4.Follow up newborn clinic $(\mathrm{n}=15)$ & 2 & 13.3 & 13 & 86.7 \\
\hline 5.Child out-patient clinic $(\mathrm{n}=18)$ & 9 & 50.0 & 9 & 50.0 \\
\hline 6.Dental clinic $(\mathrm{n}=18)$ & 15 & 83.3 & 3 & 16.7 \\
\hline 7.Emergency clinic $(\mathrm{n}=5)$ & 1 & 20.0 & 4 & 80.0 \\
\hline
\end{tabular}


Table 12: Correlations between the knowledge score of the studied nurses about maintaining patient safety and their attitude and practice scores among the maternal and child health care centers.

\begin{tabular}{|l|c|c|}
\hline \multirow{2}{*}{} & \multicolumn{2}{|c|}{ Total knowledge score } \\
\cline { 2 - 3 } & $\mathbf{r}$ & $\mathbf{P}$ \\
\hline Total attitude score & 0.059 & 0.521 \\
\hline Practice score & & \\
1.Antenatal clinic & -0.024 & 0.926 \\
2.Family planning clinic & -0.061 & 0.787 \\
3.Vaccination clinic & 0.189 & 0.377 \\
4.Follow up newborn clinic & 0.113 & 0.688 \\
5.Child out-patient clinic & -0.218 & 0.386 \\
6.Dental clinic & -0.242 & 0.332 \\
7.Emergency clinic & -0.427 & 0.474 \\
\hline
\end{tabular}

r: Pearson' correlation coefficient 
Table 13: Relationship between socio demographic characteristics of the studied nurses and their total knowledge mean score and their total attitude score about maintaining patient safety

\begin{tabular}{|c|c|c|c|c|}
\hline Charact & \begin{tabular}{|c|}
$\begin{array}{c}\text { Total } \\
\text { knowledge } \\
\text { score }\end{array}$ \\
\end{tabular} & $\begin{array}{l}\mathbf{t} \\
\mathbf{F}\end{array}$ & $\begin{array}{c}\text { Total } \\
\text { attitude } \\
\text { score } \\
\end{array}$ & $\begin{array}{l}\mathbf{t} \\
\mathbf{F}\end{array}$ \\
\hline $\begin{array}{cc}\text { Age (in years) } \\
-\quad(30-<40) \\
-\quad(40-<50) \\
-\quad \geq 50\end{array}$ & $\begin{array}{l}25.785 .816 \\
\mathbf{2 7 . 8 2 5 . 2 2 2} \\
26.625 .695\end{array}$ & $\begin{array}{l}24.748 \\
0.000 *\end{array}$ & $\begin{array}{c}45.6111 .163 \\
\mathbf{4 7 . 5 7 6 . 2 5 8} \\
7.106 .308\end{array}$ & $\begin{array}{l}0.971 \\
0.333\end{array}$ \\
\hline $\begin{array}{|cc|}\text { Place of residence } \\
- & \text { Rural } \\
- & \text { Urban } \\
\end{array}$ & $\begin{array}{l}27.675 .688 \\
26.995 .476 \\
\end{array}$ & $\begin{array}{l}50.120 \\
0.000 *\end{array}$ & \begin{tabular}{|l}
49.504 .218 \\
46.697 .506 \\
\end{tabular} & $\begin{array}{l}68.603 \\
0.000^{*}\end{array}$ \\
\hline \begin{tabular}{|l} 
Qualification \\
$-\quad$ Technician \\
nursing (3 years) \\
- $\quad$ Technician \\
nursing (5 years) \\
- $\quad$ Bachelor \\
\end{tabular} & $\begin{array}{l}27.105 .559 \\
26.275 .623 \\
29.003 .367\end{array}$ & $\begin{array}{l}51.668 \\
0.000 *\end{array}$ & \begin{tabular}{|}
47.186 .847 \\
45.6410 .298 \\
49.256 .702
\end{tabular} & $\begin{array}{l}70.100 \\
0.000 *\end{array}$ \\
\hline \begin{tabular}{|cl} 
Years of experience \\
$-\quad(10-<20)$ \\
$-\quad(20-<30)$ \\
$-\quad(30-<40)$ \\
$-\quad \geq 40$
\end{tabular} & $\begin{array}{c}26.715 .977 \\
28.405 .147 \\
25.565 .484 \\
28.000 .00\end{array}$ & $\begin{array}{l}0.815 \\
0.416\end{array}$ & $\begin{array}{c}46.0011 .710 \\
46.186 .631 \\
48.735 .366 \\
46.000 .00\end{array}$ & $\begin{array}{l}23.968 \\
0.000^{*}\end{array}$ \\
\hline
\end{tabular}




\section{Discussion}

Patient safety remains one of the most vital issues facing health care now a day. Nurses are the health care professionals most liable to persist errors and prevent harm to patient's safety. Assessing the present safety climate in primary care practice is the first step to target improvements; accordingly, assessing health care provider's attitudes about issues relevant to patient safety is the first stage of developing a safety culture ${ }^{(28)}$. The aim of this study was to assess knowledge, attitudes and practices of nurses toward client safety at maternal and child health care centers. ${ }^{(29)}$

The current study revealed that all of the studied nurses were females (table I). This findings was in agreement with study conducted by Mamdouh E (2020) ${ }^{(30)}$ who assess nurses' performance regarding the implementation of patient safety measures in intensive care units in Egypt and reported that, the majority of the studied nurses were female. Also Mohamed A (2015) ${ }^{(31)}$ who assess patient safety culture in primary health care services in Alexandria, Egypt and reported that, the majority of the participants were females. This result may be due to that the greater fraction of the nurses in Egypt are females. Also this findings may be due to the dominance of females in the nursing profession and the recent involvement of males in nursing especially in primary health care centers, and may related to the studying of nursing in Egyptian universities were exclusive for females only till few years ago. The present study revealed also that the mean duration of years of experience of the studied nurses was 26.416.906 (table 1). This results may be due to that nurses worked in $\mathrm{MCH}$ centers usually had no transfer to other settings as for hospital settings.

Nurses should be able to define the concept, identify the goals and ways of implementing standards of patient safety. Which reflects acceptable level of knowledge for nurses in PHC centers regarding patient safety items. In this concept the current study showed that, three quarters of the studied nurses gave a correct answers about the instructions that must be followed up by nursing staff to prevent the spread of infection in the clinics of the center (table2) .

This result is similar to study conducted by Brasaitè et.al, (2016) ${ }^{(32)}$ who studied health care professionals' skills regarding patient safety in Finland and found that, the highest evaluated skill for staff was applying hand washing measure. This finding was in contrast with study conducted by Comunale et.al, (2018) ${ }^{(33)}$ who studied assessment of basic patient 
safety skills in residents entering the first year of clinical training in New York and found that the studied nurses scored poorly regarding adherence with hand hygiene .These results may be due to that the compliance with infection control measures may be due to availability of infection control supplies and awareness of nurses about the important of applying of infection control measures.

The present study demonstrated that more than half of the studied nurses gave incomplete correct answer about guidelines must be followed when acupuncture (table 2). This finding contradict with AbdulLateef S. J (2018) ${ }^{(34)}$ who assess injection safety practice among nurses at primary health care centers in Iraq, and reported that, $95.5 \%$ of studied nurses had attend training sessions on safe injection approaches that was reflected clearly on their awareness and performance. The result of the present study may be related to the studied nurses usually hadn't have training related to injection safety.

Furthermore, the current study revealed that more than two thirds of the studied nurses gave a correct answer about nursing practices to prevent recipient from falling risks in the center (table 2). This finding was contradicting with Smith et.al, (2015) ${ }^{(35)}$ who assess healthcare provider's perceptions and self-reported fall prevention practices in New York and mentioned that the majority $(84 \%)$ of primary care providers didn't know how to conduct fall-risk assessments and weren't conducting multifactorial risk evaluation on every patient/ client activity. He regains this result due to the workload as well as shortage of nurses in most of his studied settings and because there isn't an educational and training program me about falling risks and there isn't managerial commitment. So, an important step is to make fall prevention a routine part of clinical care.

The current study found that the mean and standard deviation of total knowledge score were 27.09+5.489 with rang (17-40). The current study also revealed that more than one third of the studied nurses had good total knowledge score and nearly one third had poor knowledge score (table 3 ). This may due to lack of patient safety courses or training in additional to inactivation of in service education program me in primary health care centers about patient safety measures.

This result was similar to the finding of a study conducted by Al-Rafay S. Set .al, (2018) (36) who evaluate nurses' skills regarding international patient safety goals at primary health care centers in Giza governorate, Egypt and found that, more than two-fifths of studied the nurses had 
good knowledge regarding patient/ client safety issues and near to one-third had poor knowledge, while the rest of them had average knowledge.

Patient safety is critical to health care quality and remains new field of patient safety culture in primary health care are limited compared to secondary care. An important first strategy to improve all aspects of health care quality is creating a culture of safety within health care organizations. An understanding of the safety culture is vital to improve the problematic practices or attitudes such as miscommunication, unwanted events and a non-punitive response to errors, which can lead to an improvement in the safety culture (climate) of primary health care 37).

A notable finding in the study was that the participants working in the antenatal and family planning service clinic had a more positive patient safety attitude than those working in pediatrics. In this regard the current study illustrated that safety climate domain had the highest score, followed by team work, job satisfaction, perception of management and working conditions. Furthermore, the current study also revealed that the majority of the studied nurses had a total positive attitude toward patient safety in maternal and child health centers (table 4). The current study result was in the same line of the study conducted by Brasaite I et al (2017) ${ }^{\text {(32) }}$ who studied healthcare professionals' knowledge, attitudes and skills regarding patient safety: a systematic literature review In Finland and reported that overall, the safety attitudes of health care professionals were positive. The professional contributions of nurses will be effective in enhancing the patient safety attitude of institutions by making the training program me continuous, revising the current training programs, preparing and carrying out the programs.

On the other hand, the current study revealed that the minority of the studied nurses had negative attitude. This finding was supported by a study conducted by Saberi M, (2017) ${ }^{(38)}$ who found that the attitude of nurses toward the patient safety culture was poor in the five items of SAQ. Moreover, it may be attributed that the nurses' negative attitude may be related to the misunderstanding of the concept of the safety, but the understanding of the safetyrelated attitudes and perceptions are very important for the protection of the patient and others.

Patient safety practice is a process, or structure which diminish the chance of adverse events resulting from directly contact to the healthcare system over a range of diseases and procedures. It 
includes the following; identify patients/ clients correctly, improve effective communication, ensure medication safety, reduce the risk of health care-associated infections, reduce the risk of patient/ client harm resulting from falls, and ensure safe surgery ${ }^{(39-40)}$.

In relation to studied nurses practices related to patient safety, the present study found that majority of studied nurses done washing hands before procedure and wear gloves incompletely. More than one third of studied nurses in antenatal clinic didn't perform practices related to uses hand rub for hand washing with water and soap/alcohol and checking cleanliness of the examination room (table 5 ). These findings corresponding to study conducted by Salama O et al (2017) ${ }^{(41)}$ who studied attitudes and compliance with hand hygiene practices among health care workers in Alexandria Main University Hospital who found that the level of noncompliance was much higher, as only $4 \%$ of Health Care Workers (HCWs) washed or rub their hands before touching the patient. This may be attributed to overload of cases in antenatal clinic that nurses haven't time to hand washing before, between cases and wear gloves.

Concerning to assessment of the studied nurses according to their nursing practice toward maintaining patient safety in family planning counseling clinic (table 6). The current study revealed that most of the studied nurses uses disposable syringes during IM\IV injection and more than three quarters of the studied nurses use client record, explains methods of family planning about how to use it and sterilizes family planning equipment. This results was similar to the study conducted by Nasr EL et al (2016) ${ }^{(42)}$ who studied association between quality of family planning services and client's satisfaction level in maternal and child health centers in Port Said city, Egypt and reported that all nurses perform infection control measures in family planning room and follow up counseling instructions by explaining methods of family planning . These results may be justified by supervisory visits, from infection control unit in the ministry of health especially, on the family planning clinics.

Regarding assessment of the studied nurses according to their nursing practice toward maintaining patient safety in vaccination clinics, the current study reported that all of the studied nurses perform practice completely regarding checking age indications for the vaccines and administering vaccines to the correct age groups , and put used needles and syringes immediately in a sharps container following administration (table 7) .This 
finding was supported by the study done by El Shazly H (2015) ${ }^{(43)}$ who studied assessment knowledge and practice of healthcare providers as regards routine children vaccination in primary healthcare facilities of Quewisna District, Menoufia Governorate in Egypt, and found that availability of equipment needed for the session and disposal boxes in vaccination clinic. This result may be due to nurses strive to carried out $\mathrm{MCH}$ protocols and guidelines of nursing care according to vaccination clinical items.

The current study also illustrated that, more than half of the studied nurses perform practices incompletely regarding the nurse was using proper hygienic techniques to clean hands before vaccine administration, between clients and anytime when hands become soiled (table 7 ) . This findings was in agreement with study conducted by Metwali F (2019) ${ }^{(44)}$ who assess nurse's role in vaccination sessions in primary health care units in ElHossain City at Sharkia Governorate, Egypt and found that about $89.5 \%$ of them not washing their hands after vaccination session. This may be attributed to lack of knowledge about infection control precaution and importance for hand washing or due to shortage in nursing staff and increase work overload and their responsibilities.
The studied nurses regain the cause of not wash hands and wear gloves to the lack of information about the efficacy of these two measures, they think that gloves are not required for intramuscular, subcutaneous and intradermal injection in emergency clinic. Also this may be due to misconceptions among nurses regarding wearing gloves and washing hands or alcohol based hand rubbing.

The present study revealed that, the majority of studied nurses' practice score was satisfactory in vaccination clinic as the practice level of this study was high (table 11). However, this findings contradicted with study findings of Metwali1 F ( 2019 ) (44) who reported that more than half $60.5 \%$ from studied nurses had not adequate practice in vaccination session. He mentioned that may be due to lack of their knowledge about vaccination. It may be justified to that process of cold chain was being made perfect and this result in high scoring of observing items in vaccination clinics.

Furthermore, the current study findings showed that there was non-significant correlation between total knowledge, practice and total attitude score of the studied nurses regarding patient safety (table 12). However, more than one third of studied nurses who had good knowledge score had positive attitude and 
satisfactory practices. This result contradicted with, the study conducted by El-Azzab S et al (2019) ${ }^{(46)}$ who studied nurses' knowledge, attitudes, and skills towards patients' safety in Assiut, Egypt and reported that, there was positive relationships between knowledge, attitudes, and skills, and a highly statistically significant difference was detected between studied nurses' skills and attitudes regarding patients safety, This results may be attributed to it seems that having nurses experience and clinical experience in addition to participating in workshops improves the level of knowledge and practice of nurses from the principles of infection control, patient safety in primary health care centers .

Regarding effect of sociodemographic characteristic on studied nurses total knowledge score, the present study also found that there was a statistically significant relationship between total knowledge score and all items of the studied nurses sociodemographic characteristics ( table 13 ). The current study indicated that there was statistically significant relation between nurses' knowledge and their age that most of the nurses were at age group of $(40-<50)$ years). This finding contradicted with a study conducted with Abdel-latif R (2018) (47) who evaluated nurse's adherence to the national standards of patient in Egypt and reported that there was no statistical significant correlation between nurses' compliance to national levels of patient safety and nurses average age during afternoon and night shift, while there is a negative correlation during morning shift. And he mentioned that these results could be due to the distribution of nurses with different ages among all working shifts but sometimes the younger nurses worked at morning shift because of the routine rooster which make the morning shift with increased number of young nurses. Also in the present study, there was no significant relation between knowledge and years of experience. However those who had more years of experience had better knowledge.

Concerning effect of socio demographic characteristics of the studied nurses on their total attitude score about maintaining patient safety. The current study revealed that there was a statistically significant relationship between total attitude score and all items of the studied nurses sociodemographic characteristics including residence of studied nurses, their qualification and years of experience (table 13). This finding may be due to health care professionals who received no information about patient safety during their initial professional education had more negative attitudes to teamwork 
climate, safety climate, job satisfaction, perceptions of management and working conditions than those who had. Also, this result may be due to culture or perception differences between urban and rural residence. These results are consistent with Abdi $\mathbf{Z}$ et al $2015^{(48)}$ who studied the climate of patient safety in an Iranian intensive care unit and correlated the working duration with both managers' perception and positive attitudes towards safety climate. Generally, higher working experiences, increases the individuals belonging to his work as well as increases his tolerance to changeable working condition and maintain job satisfaction, Additionally, new practitioners may be less sensitive to safety issues.

Finally, it's obviously that patient safety in primary health care settings affected more by nurse's knowledge, attitude and practices. Although there is no statistically significant relation found between this three domain in the present study but each domain has its separately important effect on providing and maintaining patient safety and safety climate in primary health care settings.

\section{Conclusion:}

Based on the findings of the present study, it can be concluded that, more than one third of the studied nurses had good total knowledge score regarding patient / client safety. The highest rate of positive attitudes toward the patient safety culture/ climate belonged to the dimension of 'the safety climate followed by team work. The stress recognition domain had the lowest score. The majority of studied nurses' total practice levels were satisfactory in vaccination clinic and family planning clinic. The more knowledge health care professionals have about patient safety, the more positive their attitudes and the better their skills regarding patient safety. There is statistically significant relationship found between total knowledge and attitude scores and the studied nurse's sociodemographic characteristics $(\mathrm{P}<0.05)$.

\section{Recommendations:}

\section{Based on the results of the present} study it was recommended that:

- All nurses working in primary health care settings should complete regular periodic in-services training programs to keep them up to date regarding patients' safety culture and safety practices.

- Written guidelines regarding patients' safety should be available in all primary health care settings, and the patients should be closely monitored for potential errors.

- Primary health care infrastructure has to be financially supported, equipped and positioned to enhance patient safety 
management implementation as well as adoption and use.

- It is finally recommended to conduct further surveys and studies that contribute to quality improvement associated with nurses' perception of safety culture /climate in primary healthcare centers.

\section{Reference}

1. Fitzsimons J, Vaughan D. Top 10 interventions in paediatric patient safety. Curr Treat Options Peds. 2015; $1: 275-85$.

2. Emanuel L, Taylor L, Hain A, Combes J, Hatlie M, Karsh B, Lau D . The patient safety education program canada (PSEP - Canada) curriculum. Canada Plenary 3: What is Patient Safety?: A Conceptual Framework. 2017. Available at: www.patient safetyinstitute.ca for further information. T2 PSEP - Canada Plenary 3 Trainer's Notes [Revised 2017]

3. World Health Organization. Patient safety Available at https://www. who.int/ patientsafety/en/. 2016.

4. WHO Director General. Patient safety: Global action on patient safety [Internet]. 72nd World Health Assembly; 2019. Available At: http://apps.who.int/ gb/ebwha/pdf_ files/WHA72/A72_26-en.pdf
5. Khoshakhlagh A, Isa Akbarzadeh E, Yazdanirad $\mathrm{S}$, Ali Sheidaei A. Analysis of affecting factors on patient safety culture in public and private hospitals in Iran.. BMC. Health Services Research , 2019; 19 (1009): 2-14.

6. Lai AY, Yuan CT, Marsteller JA. Patient safety in primary care: conceptual meanings to the health care team and patients. J Am Board Fam Med. 2020;33(5):754-64.

7. Slawomirski L, Auraaen A, Klazinga N. The Economics of Patient Safety in Primary and Ambulatory Care: Flying blind. Paris: OECD. 2018; available at :(http://www.oecd.org/health/healthsystems/The-Economics-of-PatientSafety-in-Primary-and-AmbulatoryCare-April2018.pdf, accessed 23 July 2019).

8. Webair H, Al-assani S, Al-haddad R , Al-Shaeeb W, Alyamani s , Assessment of patient safety culture in primary care setting, Al-Mukala, Yemen. BMC Family Practice. 2015; 16 (136): 1-9.

9. El- Shabrawy E, Anwar M, Mostafa $Z$. Assessment of patient safety culture among health care workers in Beni Suef University Hospital, Egypt. The Egyptian Journal of Community Medicine, 2017 ; 35 (1) :1-10. 
10. El-Sherbiny N, Ibrahim E, AbdelWahed W. Assessment of patient safety culture among paramedical personnel at general and district hospitals, Fayoum Governorate, Egypt Journal of the Egyptian Public Health Association. 2020; 95(1):41-8.

11. Wang Y, Han H, Qiu L, Liu c, Wang Y, Liu W. Development of a patient safety culture scale for maternal and child health institutions in China: a cross-sectional validation study. BMJ Open. 2019;9(1): 1-14.

12. Weel C, Michael R. Kidd A. Why strengthening primary health care is essential to achieving universal health coverage, CMAJ , 2018; (15)190: 463-6.

13. Panagioti M , Khan M , Keers R , Abuzour A. Preventable patient harm across health care services: A Systematic Review and Meta-analysis (Understanding Harmful Care). A report for the General Medical Council. 2017; (1): 4-91.

14. Vaismoradi M, Tella S, A Logan P, Khakurel J, Vizcaya-Moreno F. Nurses' adherence to patient safety principles: A Systematic Review. Int J Environ Res Public Health, 2020;17(6):1-15.

15. Abdulmutalib I, Safwat A. Nursing strategies for reducing medication errors. Egyptian Journal of Nursing \& Health Sciences, 2020 ; (1) 1:77-95.
16. Armstrong K. The safe storage and management of vaccines. Safely administering and storing vaccines in the community setting. British Journal of Community Nursing September , 2017 ; 22 (9):226-9.

17. Mula j , Estrada j. Impact of nursepatient relationship on quality of care and patient autonomy in decisionmaking. International Journal of Environmental Research and Public Health , 2020; 835 (17): 1-24.

18. Lahti C, Holmström A, Pennanen P, Airaksinen M. Facilitators and barriers in implementing medication safety practices across hospitals within 11 European Union countries. Pharmacy Pract (Granada), 2019; 17 (4): 1583-20.

19. Ashwin Vasan, Mabey D, Helen-Ann Brown Epstein S, Stephen D. Support and performance improvement for primary health care workers in lowand middle-income countries: a scoping review of intervention design and methods, Health Policy and Planning, 2017: 32( 3): 437-52.

20. Phelan E, Mahoney J, Voit J, Stevens J. Assessment and management of fall risk in primary care settings. Med Clin North Am, 2015;99(2):281-93.

21. Aiken L, Sloane D, Barnes H, Cimiotti J, Jarrín O, McHugh M. Nurses' And Patients' appraisals show patient safety 
In hospitals remains a concern. Health Aff (Millwood)J. 2018; 37 (11): 1744-51

22. Alonazi, N, Alonazi A, Saeed El, Mohamed S. The perception of safety culture among nurses in a tertiary hospital in Central Saudi Arabia. Sudanese Journal of Paediatrics, 2016 ; 16(2): 51-8.

23. Khan H , Ahmad A, Mehboob R. Nosocomial infections and their control strategies. Asian pacific journal of tropical biomedicine .2015;5(7): 509-14.

24. Rohmani N , Winahyu Sar I. Adaptation and validation of safety attitude questionnaire ambulatory (SAQ-A) in Indonesian primary health care facilities. Journal Kedokteran dan Kesehatan , 2019 ;19 ( 2): 43-8 .

25. Singh H, Meyer A, Thomas E. The frequency of diagnostic errors in outpatient care: estimations from three large observational studies involving US adult populations. BMJ Qual Saf , 2019; 23(9):727-31. Available at (https://www.ncbi.nlm.nih.gov/pubmed 124742777, accessed 13 February 2019).

26. KallbergA ， EhrenbergA，FlorinJ , OstergrenJ, Goransson K. Physicians' and nurses' perceptions of patient safety risks in the emergency department. International Emergency Nursing , 2017; 33(1): 14- 19.
27. Enblom A , Johnsson A . Type and frequency of side effects during pC6 acupuncture: observations from therapists and patients participating in clinical efficiency trials of acupuncture. Acupuncture in Medicine j, 2017;35(6): 421-42 .

28. El Shafei A, Zayed M . Patient safety attitude in primary health care settings in Giza, Egypt: Cross- sectional study. International Journal Health Plann Mgmt, 2019;34(1):851-61.

29. Ivetic V, PoplasS, Pašić K, Selič P. Beliefs and viewpoints of family medicine physicians on approaches to identify and treat medically unexplained symptoms. Acta MedicoBiotechnica, 2016;9(1):47-57.

30. Mamdouh E, Mohamed H, Abdelatief D . Assessment of nurses' performance regarding the implementation of patient safety measures in intensive care units Ain Shams University Egypt. Egyptian Journal of Health Care, 2020; 11(1):91-7

31. Mohamed A, Ali M , Gewaifel G . Assessment of patient safety culture in primary healthcare services in Alexandria, Egypt. Global Journal of Epidemiology and Public Health.2015; 2(1): 5-14.

32. Brasaite I, Kaunonen M, Martinkenas A. Health care professionals' knowledge regarding patient safety. 
Clinical nursing research , 2017; 26(3): 285-300.

33. Comunale M, Sandoval, Ma, Toya La . An assessment of basic patient safety in resident entering the first year of clinical training, Journal of patient safety , 2018;14(2): 112-4.

34. Abdul- Lateef S , Sulaiman M , Jasim M. Assessment of injection safety practice among nurses at primary health care centers in Mosul. Mosul Journal of Nursing. 2018; 6 (1): 11-59

35. Smith M, Judy A. Ehrenreich S, Schuster W , Cherry C, Ory M . Healthcare providers' perceptions and self-reported fall prevention practices: findings from a large New York health system. Frontiers in public health , 2015; 3(1): 17-3.

36. Al-Rafay S, Shafik S, Fahem $S$. Assessment of nurses' performance regarding international patient safety goals at primary health care settings. IOSR Journal of Nursing and Health Science (IOSR-JNHS) , 2018 ; 7 (6): 59-67.

37. AL Lawati M, Dennis S, Abdulhadi N. Patient safety and safety culture in primary health care: a systematic review. BMC Family Practice, 2018; 19(104): 2-12.

38. Saberi M, Jamshidi E, Rajabi F, Seydali E, Bairami F. Attitude of nurses toward the patient safety culture: A Cross-sectional study of the hospitals in Tehran, Iran. Patient Safety Quality Improvement Journal ， 2017; 5(3):554- 560.

39. Gizaw A , Hailu F, Negese D. Perception towards patient safety practice and associated factors among health care providers of Jimma Zone Public Hospitals. Adv Tech Biol Med , 2018; (1)6:3-25.

40. Kear T, Ulrich B. Patient safety and patient safety culture: Foundations of Excellent health care delivery. Nephrology Nursing Journal. 2014; 41(5): 447-456, 505.

41. Salama O, Elweshahi H , Abd El Raheem A. Knowledge, attitudes and compliance with hand hygiene practices among health care workers in Alexandria Main University Hospital. Journal of High Institute of Public Health ， 2017;47(2):39-47.

42. Nasr EL , Hassan H . Association between quality of family planning services and client's satisfaction level in maternal and child health centers in Port Said city. Journal of Nursing Education and Practice, 2016; 61(1):91-7.

43. El Shazly H, Khalil N, Ibrahem R, Abdel Wahed S . Knowledge and practice of healthcare providers as 
regards routine children vaccination in primary healthcare facilities of Quewisna District, Menoufia Governorate Departments of Public Health and Community Medicine and Family Medicine, Egypt, 2016;29(4):1018-24.

44. Metwali F, Aly S, Farg H, ElShahat M . Assessment of nurses' role in vaccination sessions in primary health care units in El-Hossania City at Sharkia Governorate. Community Health Nursing Department, Faculty of Nursing Zagazig University, Egypt Global Animal Science Journal- GAS , 2019; 7(2):1-14.

45. El-Azzab S, Abd El-Aziz A. Nurses' knowledge, attitudes, and skills towards psychiatric patients' safety. Journal of Nursing and Health Science (IOSR-JNHS), 2018 ; 7(3): 13-25.

46. nAbdel-latif R, Ezz Elden N, AbdelAlim E. Nurses adherence to the national standards of patient safety. Medical Journal Cairo Univ , 2018; 86( 6): 3359-67.

47. Abdi Z, Delgoshaei B, Ravaghi H, Abbasi M, Heyrani A. The culture of patient safety in an Iranian intensive care unit. Journal Nurs Manag , 2015;23(3):333- 45 